\title{
Implementation of Novel Optimization Algorithm for Optimal Placement and Sizing of Capacitor Banks in Radial Distribution Systems for Power Loss Minimization and Net Savings Maximization
}

\author{
T Vinod Kumar \\ PG Scholar \\ Department of Electrical and Electronics \\ Engineering, Sir C. R. Reddy College of \\ Engineering, Eluru-534007, Andhra Pradesh, India
}

\author{
I Satish Kumar \\ Associate Professor \\ Department of Electrical and Electronics \\ Engineering, Sir C. R. Reddy College of \\ Engineering, Eluru-534007, Andhra Pradesh, India
}

\begin{abstract}
In this paper, a new algorithm is implemented to solve optimal placement of capacitors in radial distribution systems in two ways that is, optimal placement of fixed or Discrete size of capacitor banks (Variable Locations Discrete sizing Capacitor banks-VLDC) and optimal sizing and placement of capacitors (Variable Locations Continues sizing of Capacitors-VLCC) for real power loss minimization and net savings maximization. The new algorithms Bat Algorithm (BA): search for all possible locations in the system along with the different sizes of capacitors, in which the optimal sizes of capacitor are chosen to be standard sizes that are available in the market. To check the feasibility, the proposed algorithms are applied on standard 34 and 85 bus radial distribution systems. And the results are compared with results of other methods like particle swarm optimization (PSO), harmonic search (HS), genetic algorithm (GA) artificial bee colony (ABC) teaching learning based optimization (TLBO) and plant growth simulation algorithm (PGSA), as available in the literature. The proposed approaches are capable of producing high-quality solutions with good performance of convergence. The entire simulation has been developed in MATLAB R2010a software.
\end{abstract}

\section{Keywords}

Optimization, capacitor banks, power loss minimization, net savings maximization, radial distribution systems, BAT algorithm, VLCC, VLDC etc

\section{INTRODUCTION}

The analysis of power distribution systems is an important area of research due to the fact that, it is the final link between the bulk power system and consumers. However, reactive power flow in a distribution network always cause high power losses. The reactive power support is one of the wellrecognized methods for the reduction of power losses together with other benefits; such as loss reduction, power factor correction, voltage profile improvement to the utmost extent under various operating constraints. The shunt capacitor is one of the basic equipment to full fill these objectives. Therefore it is important to find optimal location and sizes of capacitors in the system to achieve the above mentioned objectives.

Numerous methods for solution to the optimal placement of capacitor with a view to minimizing losses have been suggested in the literature based on both traditional mathematical methods and more recent heuristic approaches.
Over the last two decades, the studies on meta-heuristic techniques have shown that the most of the difficulties of classical methods can be eliminated by applying these techniques.

Several heuristic methods have been developed in the last decade for optimal capacitor placement. Prakash and Sydulu used PSO [1] approach for finding the optimal size and location of capacitors in radial distribution system. Kalyuzhny et al. proposed GA [2] as an optimization tool to place shunt capacitor on distribution system under capacitor switching constraints. Rao et al. [3] presented plant growth simulation algorithm (PGSA) for capacitor placement in radial distribution systems which determine the optimal locations and size of capacitor to improve the voltage profile and reduction of power losses. Raju et al. presented direct search algorithm (DSA) [4] to find the optimal size and location of fixed and switched capacitors in a radial distribution system to maximize the savings and minimize the power loss. Some other heuristic methods such as tabu search [5], the harmony search algorithm [6], ant colony optimization-based algorithm [7] and a simulated annealing technique [8], and TLBO [9] to solve capacitor placement optimization problems. A comprehensive survey on the various heuristic optimization techniques applied to determine the optimal capacitor placement and size is presented in [10].

New meta-heuristic Bat algorithm was proposed by Xin-SheXang in [11]. In this paper, both Bat optimization algorithms are utilized to determine the optimal sizes and locations of shunt capacitors. However, from the literature review it is seen that the application of Bat algorithm for optimal capacitor placement problem of distribution system has not been explored in previous works. This motivates the authors to use Bat algorithm to locate optimal position and rating of capacitor in radial distribution system to minimize power loss and maximize the net savings. The present work describes the implementation of Bat algorithm for optimal placement of capacitors in two different ways. This problem is formulated as a nonlinear constrained mixed discrete-continuous optimization problem. In order to show the effectiveness of proposed approaches: they have been tested on the IEEE 34 and 85 bus radial distribution networks and the results are compared with the particle swarm optimization (PSO), harmonic search (HS) and some other algorithms. Different simplified methods of normal distribution load flow and other special techniques have been proposed in the literature [12, $16]$; these deal mainly with high ratio of $\mathrm{R} / \mathrm{X}$ in distribution 
systems. The distribution power flow suggested in [17] is used in this study.

\section{OBJECTIVE FUNCTION FORMULATION}

\subsection{Objective Function}

Optimal capacitor placement in radial distribution system reduces the active power losses and improves the voltage profile. Reduction in power loss leads to the reduction in energy loss cost. However, the capacitor placement increases the installation and investment cost. Therefore the objective of capacitor placement is to maximize the annual net saving by minimizing the total annual cost of system, subjected to specific operational constraints. Mathematically, the objective function of the problem is formulated as,

Maximize

$S=\left\{K_{e}\left(P_{l b}-P_{l a}\right) T-\propto\left[C_{i} N_{c}+C_{p} \sum_{i=1}^{N_{c}} Q_{c}(i)\right]-C_{0} N_{c}\right\}$

Where $\mathrm{S}$ is the annual net savings, $\mathrm{P}_{\mathrm{lb}} \& \mathrm{P}_{\mathrm{la}}$ are the total active power loss before and after compensation respectively, $\mathrm{K}_{\mathrm{e}}$ is the energy cost per $\mathrm{KWh}, \alpha$ is the depreciation factor, $\mathrm{T}$ is the time period in hours, $\mathrm{C}_{\mathrm{i}}$ is the installation cost of capacitor per location, $\mathrm{N}_{\mathrm{c}}$ is the number of compensated buses where capacitors are to be placed, $\mathrm{C}_{\mathrm{p}}$ is the purchase cost of capacitor per $\mathrm{kVAR}, \mathrm{C}_{0}$ is the capacitor operating cost per location and $\mathrm{Q}_{\mathrm{c}}(\mathrm{i})$ is the amount of reactive power of installed capacitor at bus $\mathrm{i}$.

\subsection{Constraints}

The objective function is subjected to following constraints:

- The voltage magnitude must kept within the specified limits at each bus:

$$
V_{\min } \leq V \leq V_{\max }
$$

Where $\mathrm{V}_{\min }, \mathrm{V}_{\max }$ are the lower and upper limits of bus voltage, respectively.

- The apparent power flow through the line must be less than the maximum apparent power admissible for the line and it is expressed as

- $\quad S_{i} \leq S_{\text {imax }} \quad i=1,2, \ldots n b$

Where $n b$ is the number branches, $S_{i}$ is the apparent power flow of the $i^{\text {th }}$ branch and $S_{\text {imax }}$ is the maximum apparent power flow of the $\mathrm{i}^{\text {th }}$ branch.

- From practical limitation, maximum compensation by using capacitor bank is limited to the total reactive power demand.

$$
\sum_{i=1}^{N_{c}} Q_{c}(i) \leq \sum_{j=1}^{N_{l}} Q_{D}(j)
$$

Where $\mathrm{N}_{l}$ is the number of load buses and $\mathrm{Q}_{\mathrm{D}}(\mathrm{j})$ is the reactive power demand of load at bus $j$.

- Capacitors are available in discrete sizes so shunt capacitors to be dealt with multiple integers of the smallest capacitor size available and it may be mathematically expressed as

$$
Q_{c}(i) \leq L Q_{s}
$$

Where, $\mathrm{Q}_{\mathrm{s}}$ is the smallest capacitor size available and $\mathrm{L}$ is an integer multiple.

\section{PROPOSED ALGORITHM}

\subsection{Bat Algorithm}

The majority of heuristic and meta-heuristic algorithms have been derived from the behaviour of biological systems and/or physical systems in nature. The Bat Algorithm (BA) is based on the echolocation behaviour of bats, proposed by Xin-SheXang for engineering optimization in [11]. If we idealize some of the echolocation characteristics of micro bats, we can develop various bat-inspired algorithms or bat algorithms. For simplicity, we now use the following approximate or idealized rules:

1) All bats use echolocation to sense distance, and they also 'know' the difference between food/prey and background barriers in some magical way;

2) Bats fly randomly with velocity $V_{i}$ at position $X_{i}$ with a fixed frequency $f_{\min }$, varying wavelength $\lambda$ and loudness $\mathrm{A}_{0}$ to search for prey. They can automatically adjust the wavelength (or frequency) of their emitted pulses and adjust the rate of pulse emission $r \in[0,1]$, depending on the proximity of their target.

3) Although the loudness can vary in many ways, we assume that the loudness varies from a large (positive) $\mathrm{A}_{0}$ to a minimum constant value $\mathrm{A}_{\min }$. Another obvious simplification is that no ray tracing is used in estimating the time delay and three dimensional topography. Though this might be a good feature for the application in computational geometry, however, we will not use this as it is more computationally extensive in multidimensional cases.

In addition to these simplified assumptions, we also use the following approximations, for simplicity. In general the frequency $\mathrm{f}$ in a range $\left[f_{\min }, f_{\max }\right]$ corresponds to a range of wavelengths $\left[\lambda_{\min }, \lambda_{\max }\right]$. For example a frequency range of [20 kHz, $500 \mathrm{kHz}$ ] corresponds to a range of wavelengths from $0.7 \mathrm{~mm}$ to $17 \mathrm{~mm}$

For a given problem, we can also use any wavelength for the ease of implementation. In the actual implementation, we can adjust the range by adjusting the wavelengths (or frequencies), and the detectable range (or the largest wavelength) should be chosen such that it is comparable to the size of the domain of interest, and then toning down to smaller ranges. Furthermore, we do not necessarily have to use the wavelengths themselves; instead, we can also vary the frequency while fixing the wavelength $\lambda$. This is because $\lambda$ and $\mathrm{f}$ are related due to the fact $\lambda / f$ is constant. For simplicity,

we can assume $f \in\left[0, f_{\max }\right]$. We know that higher frequencies have short wavelengths and travel a shorter distance. For bats, the typical ranges are a few metres. The rate of pulse can simply be in the range of $[0,1]$ where 0 means no pulses at all, and 1 means the maximum rate of pulse emission. Based on these approximations and idealization, the basic steps of the Bat Algorithm (BA) can be summarized as the pseudo code. And the flowchart for BA is given in Fig. 1. 


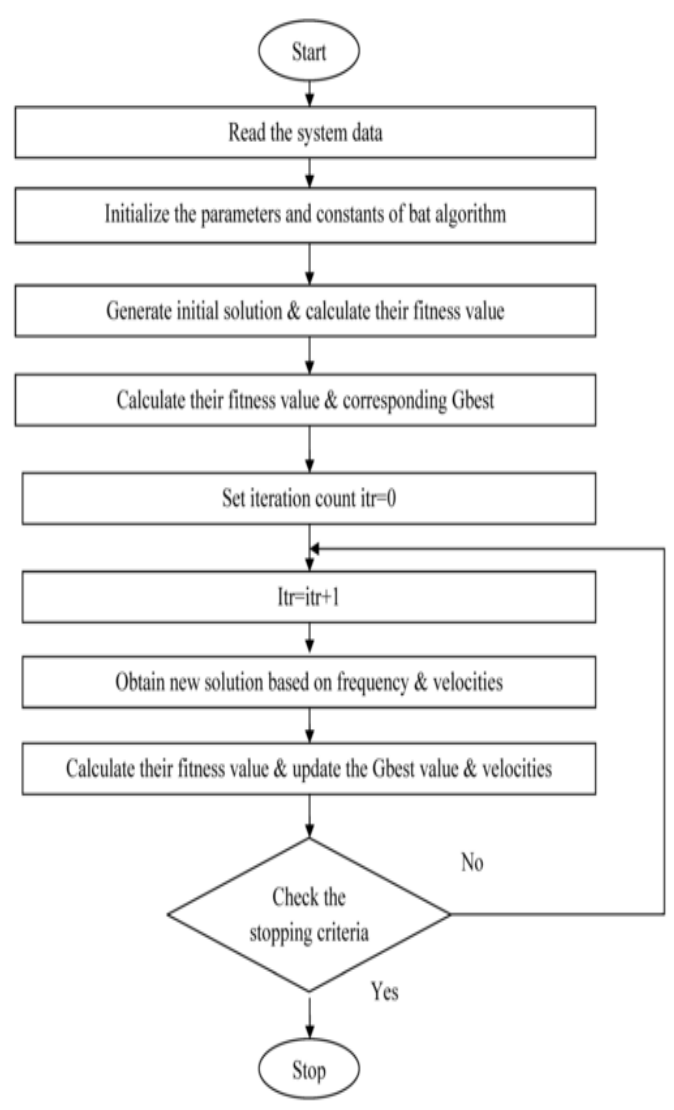

Fig 1 Flowchart for implementation of BAT algorithm

\subsection{Pseudo Code for BAT Algorithm}

Objective function $\mathrm{f}(\mathrm{x}), \mathrm{x}=\left(\mathrm{x}_{1}, \ldots, \mathrm{x}_{\mathrm{d}}\right) \mathrm{T}$

Initialize the bat population $x_{i}(i=1,2, \ldots, n)$ and $v_{i}$

Define pulse frequency $f_{i}$ at $x_{i}$

Initialize pulse rates $r_{i}$ and the loudness $A_{i}$

While ( $\mathrm{t}<$ Max number of iterations)

Generate new solutions by adjusting frequency and updating velocities and locations/solutions [Eqs (6) to (8)]

If $\left(\right.$ rand $\left.>r_{i}\right)$

Select a solution among the best solutions Generate a local solution around the selected best solution

\section{End if}

Generate a new solution by flying randomly

if $\left(\right.$ rand $<A_{i} \& f\left(x_{i}\right)<f(x *)$

Accept the new solutions

Increase $r_{i}$ and reduce $A_{i}$

\section{End if}

Rank the bats and find the current best $\mathrm{x}$ *

\section{End while}

In simulations, we use virtual bats naturally. We have to define the rules how their positions and velocities in a d- dimensional search space are updated. The new solutions $X_{i}^{t}$ and velocities at time step $\mathrm{t}$ are given by

$f_{i}=f_{\text {min }}+\left(f_{\text {max }}-f_{\text {min }}\right) \beta$
$V_{i}^{t}=V_{i}^{t-1}+\left(X_{i}^{t}-X_{*}\right) f_{i}$
$X_{i}^{t}=X_{i}^{t-1}+V_{i}^{t}$

Where, $\beta \in[0,1]$ is a random vector drawn from a uniform distribution. Here $\mathrm{x} *$ is the current global best location (solution) which is located after comparing all the solutions among all the $\mathrm{n}$ bats. As the product is the velocity increment, we can use either (or $\lambda_{i}$ ) to adjust the velocity change while fixing the other factor (or), depending on the type of the problem of interest. In our implementation, we will use $f_{\min }$ $=0$ and $f_{\max }=100$, depending the domain size of the problem of interest. Initially, each bat is randomly assigned a frequency which is drawn uniformly from $\left[f_{\min }, f_{\max }\right]$.The update of the velocities and positions of bats have some similarity to the procedure in the standard particle swarm optimization as essentially controls the pace and range of the movement of the swarming particles. To a degree, BA can be considered as a balanced combination of the standard particle swarm optimization and the intensive local search controlled by the loudness and pulse rate.

\section{RESULTS AND DISCUSSION}

The performance and effectiveness of the proposed algorithm have been tested on 34-bus and 85-bus radial distribution system for maximization of net savings through real power loss minimization. Two approaches has been presented in this paper i.e., the first approach describe the optimal placement of fixed capacitor banks and the second approach describe optimal sizing as well as placement for capacitors in radial distribution systems. The constants used in the calculation of net saving are given [18] in Table 1. A number of trails on the performance of the applied algorithms have been carried out on the test systems to determine the most suitable algorithm parameters. The tuned parameters of BAT algorithm are given in Table 2.

Table 1 Constants used in computation of net saving/ year

\begin{tabular}{|l|l|l|}
\hline S.No & Parameter description & Value \\
\hline 1 & Average energy cost $\left(\mathrm{K}_{\mathrm{e}}\right)$ & $\$ 0.06 / \mathrm{kW} \mathrm{h}$ \\
\hline 2 & Depreciation factor $(\alpha)$ & $20 \%$ \\
\hline 3 & Purchase cost $\left(\mathrm{C}_{\mathrm{p}}\right)$ & $\$ 25 / \mathrm{kVAR}$ \\
\hline 4 & Installation cost $\left(\mathrm{C}_{\mathrm{i}}\right)$ & $\$ 1600 /$ location \\
\hline 5 & Operating cost $\left(\mathrm{C}_{\mathrm{o}}\right)$ & $\$ 300 /$ year/location \\
\hline 6 & Hours per year $(\mathrm{T})$ & 8760 \\
\hline
\end{tabular}

\subsection{4-Bus Test System Numerical Results}

The 34-bus test case consists of a main feeder and 4 subfeeders (laterals) radial distribution system as shown in Fig. 2.The data of the system is obtained from [19]. The total load of the system is $4636.5 \mathrm{~kW}$ and $2873.5 \mathrm{kVAR}$. The rated voltage of the system is $11 \mathrm{kV}$. After an initial load flow using Backward/Forward Sweep method for an uncompensated system, the active power loss is $221.7235 \mathrm{~kW}$. 


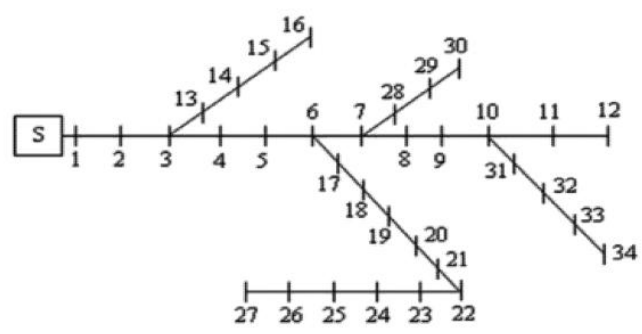

Fig 2 Single line diagram for 34-bus radial distribution system

Table 2 Description of algorithm parameters

\begin{tabular}{|l|l|l|}
\hline $\begin{array}{l}\text { BAT } \\
\text { Algorithm } \\
\text { Parameters }\end{array}$ & Description & Value \\
\hline$P o p$ & Population of Bats & 150 \\
\hline$D$ & $\begin{array}{l}\text { Dimensional search space of } \\
\text { a bat }\end{array}$ & $3 \& 8$ \\
\hline$A$ & Loudness & 0.50 \\
\hline$R$ & Pulse rate & 0.50 \\
\hline$f_{\min }$ & Minimum frequency & 0.00 \\
\hline$f_{\max }$ & Maximum frequency & 2.00 \\
\hline Maxitr & $\begin{array}{l}\text { Maximum number of } \\
\text { generations }\end{array}$ & 150 \\
\hline
\end{tabular}

To observe the effectiveness of the implemented algorithms, the results obtained in two approaches were compared with the other techniques like PSO [1], ABC [18], HS [19], GA [20] and EA [21] in the literature. Table 3 shows, the optimal locations and sizes of capacitors, total kVAR compensated, total active power loss, percentage of loss reduction and annual net savings of proposed algorithms along with existing algorithms. For this test system three capacitors are optimally placed and sized in two ways. First the locations and sizes of fixed capacitor banks are obtained by Bat algorithm are 10, 19, 24 and 750, 750, $750 \mathrm{kVAR}$ respectively, with an active power loss of $160.6945 \mathrm{KW}$, minimum voltage is $0.9501 \mathrm{p.u}$ and annual net savings of $\$ 18967$. The convergence characteristic of the test system for Bat algorithm has been given in Fig. 3.

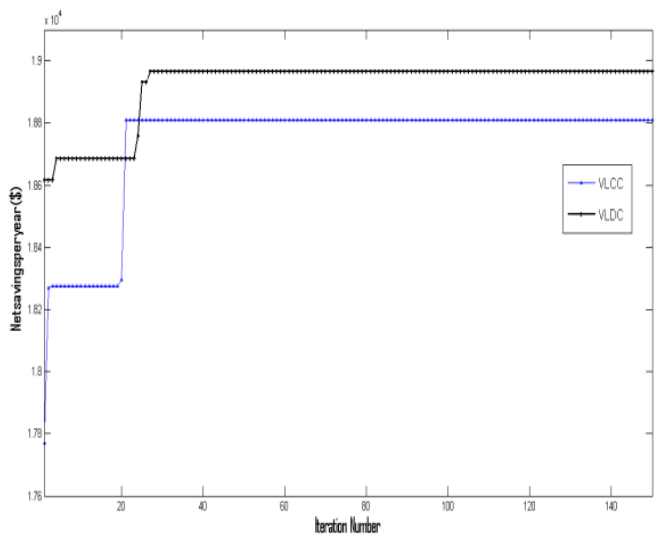

Fig 3 Comparison of algorithm for VLCC \& VLDC with respect to Net savings maximization convergence characteristics for 34-bus test system
Later, optimal locations and optimal sizes of capacitors (not fixed in size) are selected with help of same algorithms. The location and size of capacitors obtained by Bat algorithms are 10, 19, 26 and 766, 750, 734 kVAR respectively, with an active power loss of $160.99 \mathrm{~kW}$ and annual net savings of $\$ 18809$. The convergence characteristic of the test system for Bat algorithm has been given in Fig.4. From the observation of simulation results, it is noticed that annual net savings for proposed algorithm is comparatively high than other algorithms.

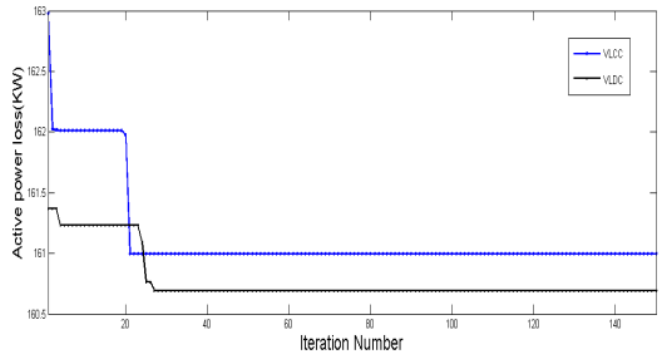

Fig4 Comparison of algorithm for VLCC \& VLDC with respect to active power loss convergence characteristics for 34-bus test system

\subsection{5-Bus Test System Numerical Results}

The 85-bus test case consists of a main feeder, 9 sub-feeders (laterals) and sub-laterals radial distribution system as shown in Fig. 5. The data of the system is obtained from [21]. The total load of the system is $2574.3 \mathrm{~kW}$ and $2622.6 \mathrm{kVAR}$.

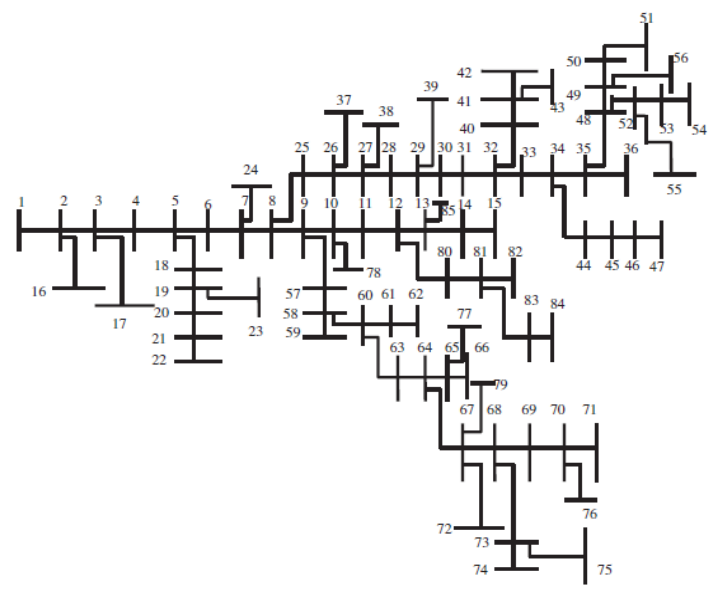

Fig 5 Single line diagram for 85-bus radial distribution system

The rated voltage of the system is $11 \mathrm{kV}$. After an initial load flow run using Backward/Forward Sweep method for an uncompensated system, the active power loss is $316.8497 \mathrm{~kW}$. In order to evaluate the effectiveness of the proposed algorithms, their results are compared with the other techniques like PSO [1], PGSA [3], DSA [4], TLBO [9] and GA [20]. Table 4, shows the optimal locations and optimal sizes of capacitors, total kVAR compensated, total active power loss, percentage of loss reduction and annual net savings of proposed and compared algorithms. For this test system eight capacitors are optimally placed and sized. For the first approach i.e. VLCC, the locations and sizes of capacitors obtained by Bat algorithm are $8,12,31,40,56,63$, 71,79 and 600, 300, 300, 150, 300, 300, 150, $150 \mathrm{kVAR}$ respectively, with a active power loss of $146.9557 \mathrm{~kW}$ and annual net savings of $\$ 73086$. 
Table 3 Comparison of results for 34-bus system

\begin{tabular}{|c|c|c|c|c|c|c|c|c|c|c|c|c|c|c|c|}
\hline \multirow{3}{*}{$\begin{array}{c}\text { S.No } \\
1\end{array}$} & \multirow{6}{*}{$\begin{array}{c}\text { Parameter } \\
\\
\text { Optimal } \\
\text { locations } \\
\text { and sizes in } \\
\text { KVAR }\end{array}$} & \multicolumn{4}{|c|}{ Proposed BAT algorithm } & \multicolumn{10}{|c|}{ 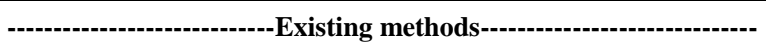 } \\
\hline & & \multicolumn{2}{|c|}{$\begin{array}{l}\text { VLCC } \\
\text { CASE }\end{array}$} & \multicolumn{2}{|c|}{$\begin{array}{l}\text { VLDC } \\
\text { CASE }\end{array}$} & \multicolumn{2}{|c|}{ PSO [1] } & \multicolumn{2}{|c|}{ EA [21] } & \multicolumn{2}{|c|}{$\begin{array}{l}\text { ABC } \\
{[18]}\end{array}$} & \multicolumn{2}{|c|}{ GA [20] } & \multicolumn{2}{|c|}{ HS [19] } \\
\hline & & 10 & 766 & 10 & 750 & 19 & 781 & 8 & 1050 & 8 & 900 & 5 & 300 & 4 & 250 \\
\hline 2 & & 19 & 750 & 19 & 750 & 20 & 479 & 18 & 750 & 18 & 900 & 9 & 300 & 11 & 750 \\
\hline 3 & & 26 & 734 & 24 & 750 & 22 & 803 & 25 & 750 & 25 & 800 & 12 & 300 & 17 & 300 \\
\hline 4 & & & & & & & & & & & & 22 & 600 & 26 & 1400 \\
\hline 5 & & & & & & & & & & & & 26 & 300 & & \\
\hline \multicolumn{2}{|c|}{ Total KVAR Placed (KVAR) } & \multicolumn{2}{|c|}{2250} & \multicolumn{2}{|c|}{2250} & \multicolumn{2}{|c|}{2063} & \multicolumn{2}{|c|}{2550} & \multicolumn{2}{|c|}{2600} & \multicolumn{2}{|c|}{1800} & \multicolumn{2}{|c|}{2700} \\
\hline \multicolumn{2}{|c|}{ Real Power losses (KW) } & \multicolumn{2}{|c|}{160.99} & \multicolumn{2}{|c|}{160.6945} & \multicolumn{2}{|c|}{169.3592} & \multicolumn{2}{|c|}{161.267} & \multicolumn{2}{|c|}{161.087} & \multicolumn{2}{|c|}{164.9586} & \multicolumn{2}{|c|}{168.48} \\
\hline \multicolumn{2}{|c|}{ Loss Reduction (\%) } & \multicolumn{2}{|c|}{27.39} & \multicolumn{2}{|c|}{27.52} & \multicolumn{2}{|c|}{23.62} & \multicolumn{2}{|c|}{27.26} & \multicolumn{2}{|c|}{27.34} & \multicolumn{2}{|c|}{25.61} & \multicolumn{2}{|c|}{24.02} \\
\hline Net $S$ & $\operatorname{ar}(\$)$ & 188 & & 1896 & & 153 & 8.83 & 171 & & 170 & 8.00 & 1774 & 0.15 & 119 & \\
\hline Elaps & & 19.9 & & 17.1 & & N/A & & $\mathrm{N} / \mathrm{A}$ & & N/A & & N/A & & N/A & \\
\hline
\end{tabular}

The net savings per year convergence characteristic of the test system for Bat algorithm has been given in Fig. 6 .

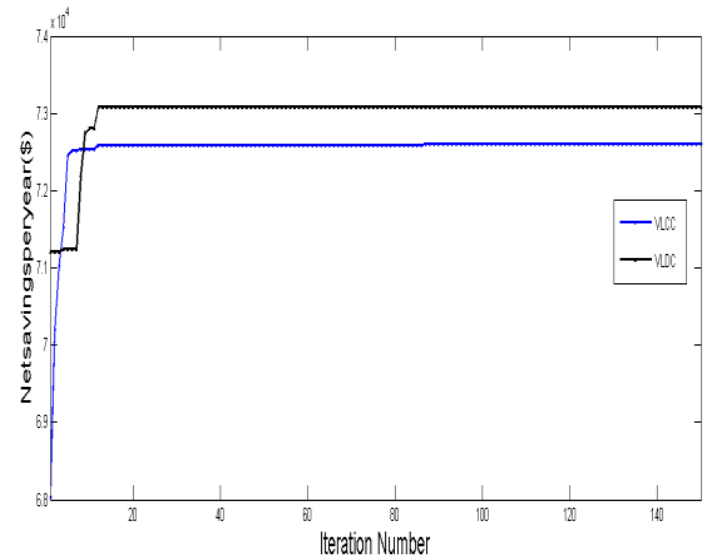

Fig 6 Comparison of algorithm for VLCC \& VLDC with respect to Net savings maximization convergence characteristics for 34-bus test system

For the second approach i.e. VLCC(Variable locations and continues sizes of capacitors) case, the locations and sizes of capacitors obtained by Bat algorithm are 7, 25, 28, 45, 48, 60, 65, 85 and 181, 323, 288, 138, 369, 400, 328, $224 \mathrm{kVAR}$ respectively, with a active power loss of $147.8715 \mathrm{~kW}$ and annual net savings of $\$ 72605$. The power loss convergence characteristic of the test system for Bat algorithm has been given in Fig. 7. From the observation of simulation results, it is noticed that annual net savings for proposed algorithm is comparatively high than other algorithms.

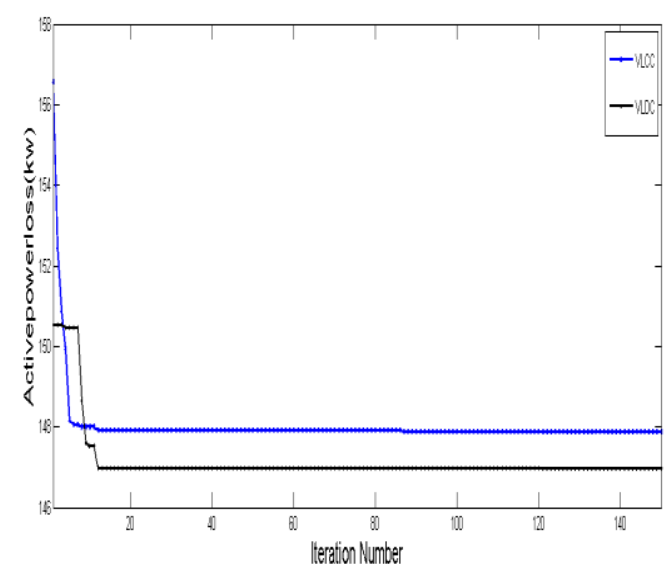

Fig 7 Comparison of algorithm for VLCC \& VLDC with respect to active power loss convergence characteristics for 34-bus test system

\subsection{Convergence Analysis and Voltage Profile Graphs}

From Table 3 and Table 4, it is observed that BAT search has been found better in view of net savings, power losses compared to existing algorithms. From Fig. 3, it is observed that Bat reached to best solution at $23^{\text {th }}$ generation for VLCC and Bat reached to best solution at $19^{\text {rd }}$ generation for VLCC in case of 34 bus test system. From Fig. 6, it is noticed that Bat reached the better solution at $20^{\text {th }}$ generation for VLDC and Bat reached to best solution at $17^{\text {rd }}$ generation for VLCC in case of 85 bus test system. Fig $8 \&$ Fig 9 shows the voltage profile graphs for 34 bus system and 85 bus system respectively. 
Table 4 Comparison of results for 85-bus system

\begin{tabular}{|c|c|c|c|c|c|c|c|c|c|c|c|c|c|c|c|}
\hline \multirow{3}{*}{$\begin{array}{c}\text { S.No } \\
1\end{array}$} & \multirow{2}{*}{ Parameter } & \multicolumn{4}{|c|}{ Proposed BAT algorithm } & \multicolumn{10}{|c|}{ 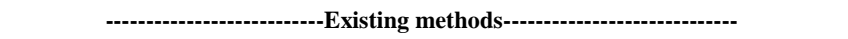 } \\
\hline & & \multicolumn{2}{|c|}{ VLCC CASE } & \multicolumn{2}{|c|}{ VLDC CASE } & \multicolumn{2}{|c|}{ PSO [1] } & \multicolumn{2}{|c|}{ PGSA [3] } & \multicolumn{2}{|c|}{ DSA [4] } & \multicolumn{2}{|c|}{ GA [20] } & \multicolumn{2}{|c|}{ TLBO [9] } \\
\hline & \multirow{19}{*}{$\begin{array}{c}\text { Optimal } \\
\text { locations } \\
\text { and sizes in } \\
\text { kVAR }\end{array}$} & 7 & 181 & 8 & 600 & 8 & 796 & 8 & 796 & 6 & 150 & 26 & 48.437 & 4 & 300 \\
\hline 2 & & 25 & 323 & 12 & 300 & 58 & 453 & 58 & 453 & 8 & 150 & 28 & 214.06 & 7 & 150 \\
\hline 3 & & 28 & 288 & 31 & 300 & 7 & 324 & 7 & 324 & 14 & 150 & 37 & 103.12 & 9 & 300 \\
\hline 4 & & 45 & 138 & 40 & 150 & 27 & 901 & & & 17 & 150 & 38 & 120.31 & 21 & 150 \\
\hline 5 & & 48 & 369 & 56 & 300 & & & & & 20 & 150 & 39 & 178.12 & 26 & 150 \\
\hline 6 & & 60 & 400 & 63 & 300 & & & & & 26 & 150 & 51 & 100 & 30 & 0 \\
\hline 7 & & 65 & 328 & 71 & 150 & & & & & 30 & 150 & 54 & 212.5 & 31 & 300 \\
\hline 8 & & 85 & 224 & 79 & 150 & & & & & 36 & 450 & 55 & 101.56 & 45 & 150 \\
\hline 9 & & & & & & & & & & 57 & 150 & 59 & 4.687 & 49 & 150 \\
\hline 10 & & & & & & & & & & 61 & 150 & 60 & 157.81 & 55 & 150 \\
\hline 11 & & & & & & & & & & 66 & 150 & 61 & 112.5 & 61 & 300 \\
\hline 12 & & & & & & & & & & 69 & 300 & 62 & 104.68 & 68 & 300 \\
\hline 13 & & & & & & & & & & 80 & 150 & 66 & 9.375 & 83 & 150 \\
\hline 14 & & & & & & & & & & & & 69 & 100 & 85 & 150 \\
\hline 15 & & & & & & & & & & & & 72 & 67.18 & & \\
\hline 16 & & & & & & & & & & & & 74 & 112.5 & & \\
\hline 17 & & & & & & & & & & & & 76 & 71.87 & & \\
\hline 18 & & & & & & & & & & & & 80 & 356.25 & & \\
\hline 19 & & & & & & & & & & & & 82 & 31.25 & & \\
\hline \multicolumn{2}{|c|}{ Total KVAR Placed (kVAR) } & \multicolumn{2}{|c|}{2250} & \multicolumn{2}{|c|}{2250} & \multicolumn{2}{|c|}{2473} & \multicolumn{2}{|c|}{2308} & \multicolumn{2}{|c|}{2550} & \multicolumn{2}{|c|}{2206.25} & \multicolumn{2}{|c|}{2700} \\
\hline \multicolumn{2}{|c|}{ Real Power losses (kW) } & \multicolumn{2}{|c|}{147.8715} & \multicolumn{2}{|c|}{146.9557} & \multicolumn{2}{|c|}{163.32} & \multicolumn{2}{|c|}{161.40} & \multicolumn{2}{|c|}{144.00} & \multicolumn{2}{|c|}{146.06} & \multicolumn{2}{|c|}{143.18} \\
\hline Loss & $\operatorname{tion}(\%)$ & & & & & & & & 88 & & & & .72 & & \\
\hline Net & /year (\$) & & & & & 658 & & & 4.36 & & 4.54 & & 0.71 & & .79 \\
\hline & ime (s) & & & & & & & & A & & & & /A & & \\
\hline
\end{tabular}

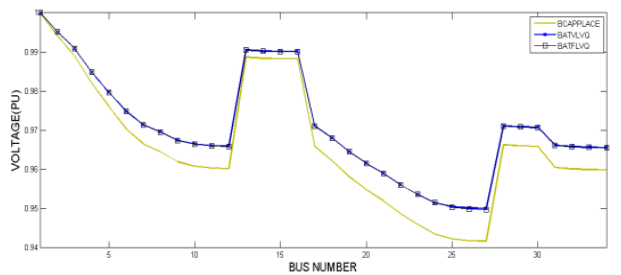

Fig 8 Comparison of voltage profile graphs before capacitor placement and after capacitor placement for 34bus system

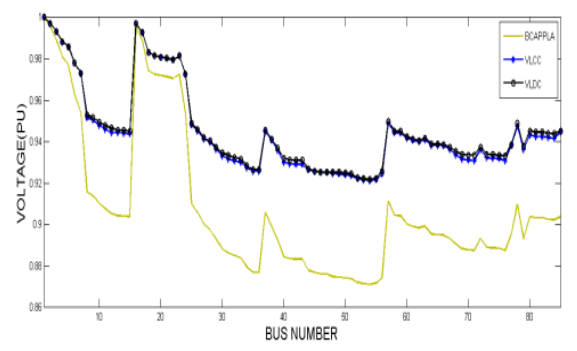

Fig 9 Comparison of voltage profile graphs before capacitor placement and after capacitor placement for 85 bus system test case

\section{CONCLUSION}

In this paper, application of Bat algorithm to the optimal placement and sizing of capacitors in radial distribution systems has been discussed in two approaches. The practical application and efficiency of these approaches are evaluated using two test systems ( 34 and 85 bus). From the comparative analysis it is concluded that, BAT algorithm gives better results than other existing methods, in terms of solution quality. According to convergence BAT converged very quickly due to simple evolution process.. In fact, for any optimization algorithm parameter tuning plays an important role in the performance of the algorithm. From the results; BAT are proved to be promising tools to solve such type of constrained objective optimization problems. So, it may be concluded that the solution given by BAT to the specific problem is best so far. Thus the results obtained pave the way for new and promising research area, utilizing BAT algorithms with proper modifications, may give better results with high convergence speed.

\section{REFERENCES}

[1] Prakash K, Sydulu M. Particle swarm optimization based capacitor placement on radial distribution systems. IEEE power engineering society general meeting; 2007 , pp.

[2] Kalyuzhny A, Levitin G, Elmakis D, Haim HB. System approach to shunt capacitor allocation in radial 
distribution system. Elect Power Syst. Res, 2000; 56(1), pp.51-60.

[3] Rao RS, Narasimham SVL, Ramalingaraju M. Optimal capacitor placement in a radial distribution system using Plant Growth Simulation Algorithm. Int. J Elect Power Energy Syst., 2011; 33(5), pp.1133-39.

[4] Raju MR, Murthy KVSR, Avindra KR. Direct search algorithm for capacitive compensation in radial distribution systems. Int J Elect Power Energy Syst., 2012; 42(1), pp.24-30.

[5] Gallego RA, Monticelli AJ, Romero R. Optimal capacitor placement in radial distribution networks using tabu search. IEEE Trans Power Syst., 2001;16(4), pp.630-7

[6] Sirjani R, Mohamed A, Shareef H. Optimal capacitor placement in a radial distribution system using harmony search algorithm. J Appl. Sci., 2010; 10(23), pp.29962996.

[7] Chang CF. Reconfiguration and capacitor placement for loss reduction of distribution systems by ant colony search algorithm. IEEE Trans Power Syst., 2008, 23(4), pp.1747-55

[8] Chiang HD, Wang JC, Cockings O, Shin HD. Optimal capacitor placements in distribution systems: part 1: a new formulation and the overall problem. IEEE Trans Power Deliv, 1990, 5(2), pp.634-42.

[9] Sneha S, Provas Kumar R. Optimal capacitor placement in radial distribution systems using teaching learning based optimization. Int. J Elect Power Energy Syst., 2004, 54, pp. 387-398.

[10] Sirjani R, Azah M, Shareef H. Heuristic optimization techniques to determine optimal capacitor placement and sizing in radial distribution networks: a comprehensive review. PRZEGLA D ELEKTROTECHNICZNY (Elect. Rev.), 2012, 88(7a), pp.1-7

[11] Yang XS. A new metaheuristic bat-inspired algorithm. In: J. Gonzalez, R., et al. (Eds.), Nature Inspired Cooperative Strategies for Optimization (NICSO 2010), 2010, SCI 284, pp. 65-74
[12] Abdellatif H, Khaled Z. Improved algorithm for radial distribution networks load flow solution. Int. J Elect. Power Energy Syst., 2011; 33(3), pp.508-14.

[13] Iwamoto S, Tamura Y. A load flow calculation method for ill-conditioned power systems. IEEE Trans Power Apparat Syst., 1981, 100(4), pp.1736-43.

[14] Ghosh S, Das D. Method for load flow solution of radial distribution network. IEE Proc Gene. Trans. Distr., 1999, 146(6), pp.641-8.

[15] Singh Sachin, Ghose T. Improved radial load flow method. Int. J Elect. Power Energy Syst. 2013, 44(1), pp.721-7.

[16] Augugliaro A, Dusonchet L, Favuzza S, Ippolito MG, Riva Sanseverino E. A backward sweep method for power flow solution in distribution networks. Int. J Elect. Power Energy Syst., 2010, 32(4), pp.271-80.

[17] Paulo M.D, Oliveira D J. The standard backward/forward sweep power flow.

[18] A Attia A, El-Fergany A, Almoataz Y, Abdelaziz, Capacitor placement for net saving maximization and system stability enhancement in distribution networks using artificial bee colony-based approach. Electrical Power and Energy Systems, 2014, 54, pp. 235-243

[19] Chis M, Salama MMA, Jayaram S. Capacitor placement in distribution system using heuristic search strategies. IEE Proc Gene. Tran. Dist. 1997, 144(3), pp. 225-30

[20] Sydulu M, Reddy VVK. Index and GA based optimal location and sizing of distribution system capacitors. In: IEEE power engineering society general meeting 2007, 24th-28th June, pp. 1-4.

[21] Ali E, Boudour M, Rabah G. New evolutionary technique for optimization shunt capacitors in distribution networks. J Elect. Eng, 2011, 62(3), pp. 163 7.

[22] Das D, Kothari DP, Kalam A. Simple and efficient method for load flow solution of radial distribution network. Electrical Power Energy Syst., 1995, 17(5), pp. $335-46$ 